\title{
NEUROGENOTOXICITY EFFECT OF DELTAMETHRIN AND AMELIORATIVE EFFECT OF VITAMIN E \& GREEN TEA ON FEMALE RATS
}

\author{
KHALEF, A.A. ${ }^{1}$, TOHAMY A.F. ${ }^{1}$, ABDEL-HAMED M.I. ${ }^{2}$ and \\ ABDALLAH A.A. ${ }^{3}$
}

1- Toxicology and Forensic Medicine Department, Faculty of Veterinary Medicine, Cairo University, Egypt

2- Biochemistry \& Molecular Biology Department, Faculty of Veterinary Medicine, Cairo University, Egypt

3- Mammalian Toxicology Department, Central Agricultural Pesticides Lab, Agricultural Research Center, Ministry of Agriculture, Egypt.

(Manuscript received 2 May 2018)

\begin{abstract}
$\mathrm{S}$ everal studies have been implicated oxidative stress and genotoxicity as important mechanisms of toxic effects of pyrethriods in the present study. The beneficial effects of vitamin $\mathrm{E}$ and green tea extract were tested in protecting the deltamethrin (DM) induced oxidative stress, genotoxicity and alterations in some amino acid neurotransmitters in brain of adult female rats . Rats were exposed to $1 \mathrm{mg} / \mathrm{Kg}$ b.wt .deltamethrin $(1 / 10$ $L_{50}$ ) alone or in combination with vitamin $E$ and/or green tea extract .The antioxidant such as catalse enzyme, reduced glutathione content, lipid peroxidation content and ChE activity were analyzed in cerebrum and cerebellum of brain excised at the end of experiment (30 days). Results showed that genotoxic effect of deltamethrin was proved by SSCP of HRas and P53 genes.Amino acids transmitters were estimated in brain of exposed DM rats . Exposure to deltamethrin resulted in a significant decrease in the activities of catalase, ChE and concentration of reduced glutathione, while the LPO levels were significantly increased in different brain regions .Also, DM exposure increases significant changes in brain amino acids. It is Interestingly that the supplementation with vitamin E or green tea extract or both resulted reversed in the deltamethrin induced antioxidant enzymes and effect on genotoxicity .Combination of both green tea and vit. E appeared to be more effective in protection than each one alone .
\end{abstract}

Keywords :Deltamethrin, Vitamin E, Green tea, Oxidative stress, Neurotoxicity, Genotoxicity

\section{1 .INTRODUCTION}

The widespread use of pesticides in public health protection and agricultural programs have caused severe environmental pollution and health hazards, particularly in developing countries, including cases of severe acute and chronic human and animal 
poisoning as well as damage to other non-target organisms: The use of pyrethroid has been increased because of the restrictions placed on many of the organophosphorous insecticides (Assayed et al., 2010).

The mechanism by which pyrethroids are thought to exert neurotoxicity is by prolonging the opening of $\mathrm{Na}^{+}$channels The toxicity of pyrethroid insecticides to mammals has received much attention in recent years because of animals exposure to these insecticides showed changes in their physiological activities and pathological features.Pyrethroids are reported to generate free radicals through hydrolytic ester cleavage and oxidative pathway by the CYP450 enzymes Induction of oxidative stress has been reported with pyrethroids such as Cypermethrin, Deltamethrine and fenvalerate ( Raina et al., 2010).

A major contribution of non-enzymatic protection against lipid peroxidation is vitamin E (a-tocopherol) a fat soluble antioxidant is a powerful chain-breaking antioxidant which plays a major protective role against oxidative stress and prevents the production of lipid peroxides by scavenging free radicals in biological membranes (Hfaiedh et al., 2012 ).

Polyphenols present abundantly in vegetables, fruits have been recognized as functionally active molecules, possessing antioxidant, anticancer and antimutagenic properties as well as, exerting protective effects against several diseases .Green tea extract (GTE) represents the richest source of natural polyphenols including catechins, aflavins and rubigin (Frei and Higdon, 2003).Polyphenols found in green tea show 20 times more powerful antioxidant activity than vitamin C .Green tea polyphenols (GTP) have demonstrated a protective effect against a spectrum of offensive oxidants, like superoxide and peroxy nitrite radicals. It was postulated that the supplementation of green tea attenuated the cyclosporine $A$ and tamoxifen-induced oxidative stress and protected against the liver injury in rats.This study was planned to evaluate the role of Vit. E and/or green tea extract as protective agents against deltamethrin-induced oxidative stress, genotoxicity and alterations in some amino acids in brain of exposed rats

\section{2 .MATERIALS AND METHODS}

\section{1 .Animals:}

Fifty albino rats of 3 months age and weighing between $150-170 \mathrm{~g}$ were obtained from the breeding unit of the Toxicology and Forensic Medicine Department, Faculty of Veterinary Medicine, Cairo University .The animals were housed in plastic cages and fed a standard laboratory diet and water ad libitum .The animals were exposed to 12 
hrs light $/ 12$ hrs dark cycle and temperature $\left(25 \pm 2{ }^{\circ} \mathrm{C}\right)$ Rats were acclimatized for one week prior to the start of experiment. All animals experiments were carried out in accordance with the guide of the care and use of laboratory animals published by the national institute of health and approved by the animal experiments local ethics committee at the Cairo University.

\section{2 .Chemicals:}

Technical grade deltamethrin (DM, 98.8 \%pure)was supplied by KZ pesticides company, Egypt .Green tea ; a Lipton green tea unilever brand, packed in the United Arab Emirates by unilever Gulf FZE, was dissolved in the drinking water at the concentration of $5 \mathrm{mgml}^{-1}$. Tea was prepared freshly three times per week and stored at $4{ }^{\circ} \mathrm{C}$ until use. The control of drinking vessels was renewed every day .Green tea extract contains epigallocatechin gallate $\left(33.7 \mathrm{mg} \mathrm{L}^{-1}\right)$ epigallocatechin $\left(268 \mathrm{mgL}^{-1}\right)$, epicatechin (90 mgL ${ }^{-1}$ )epicatechin gallate $\left(60 \mathrm{mg} \mathrm{L}^{-1}\right)$ and caffiec acid $\left(35 \mathrm{mg} \mathrm{L}^{-1}\right)$ as determined by HPLC method (Maiani et al., 1977) Vitamin E(a-tocopherol) was obtained from Sigma Aldrich chemicals, St .Louis, Mo, USA.Biodiagnostic Kits for determination of catalase activity, reduced glutathione, lipid peroxidation and acetyl cholinesterase activity were obtained from biodiagnostic company, Egypt.

\section{3 .Estimation of Median Lethal Dose (LD 50$)$.}

Twenty four mature female rats were orally administered deltamethrin with different four concentration $(6,8,10$ and $12 \mathrm{mg} / \mathrm{kg}$.) Six rats were kept as control group throughout the entire experimental period . Mortality was counted in the different groups . $L D_{50}$ was calculated ad follows equation $\left(L_{50}=\right.$ Largest dose $-\Sigma a x B / N$; where $a$ :the mean of dead rats between two successive doses, $b$ :dose difference between two successive doses, $\mathrm{N}$ :the total number of rat per group) according to Behrens and Karbers (1935).

\section{4 .Animals and Treatment.}

Fifty experimental mature female rats were randomly assigned into five equal groups; Group 1 :rats were received orally an equivalent volume of corn oil based on body weight .Group 2 :rats were orally administered ${ }^{1} / 10 L_{50}$ of deltamethrin $(1 \mathrm{mg} / \mathrm{Kg}$ b.wt )dissolved in corn oil Group 3 :rats were orally administered deltamethrin in a dose level of $1 \mathrm{mg} / \mathrm{Kg}$ b.wt beside $1 \mathrm{ml}$ of Green tea extract via gastric incubation.Group 4 : rats were orally administered the same dose of deltamethrin beside vit. $E$ in dose level $200 \mathrm{mg} / \mathrm{Kg}$ b.wt dissolved in corn oil via oral incubation.Group 5 :rats in this group were 
orally administered deltamethrin in the same previous dose beside $1 \mathrm{ml}$ green tea extract and vit. $E$ in the same dose .Deltamethrin was given to the experimental groups of rats followed by green tea extract or vit. E or both $\operatorname{after}^{1} / 2$ hour for 30 days.

\section{5 .Tissue preparation and Methods:}

After the last treatment, rats were fasted for $6 \mathrm{hrs}$.then subjected to light anesthesia and sacrificed by cervical dislocation. Brain was immediately removed, washed using chilled saline solution then perfused with phosphate buffer saline (50 mM potassium phosphate, $\mathrm{pH} 7.4$, containing $0.16 \mathrm{mgml}^{-1}$ heparin )to remove any red blood cells and clots . The tissue was homogenized in $5-10 \mathrm{ml}$ cold buffer (i.e $50 \mathrm{mM}$ potassium phosphate which composed of $9.4 \mathrm{ml}$ of $1 \mathrm{M}$ mono basic solution and $40.6 \mathrm{ml}$ of $1 \mathrm{M}$ dibasic solution and complete to $1 \mathrm{~L}$ by distilled water, $\mathrm{pH}$ 5.1, 1mM EDTA )per gram tissue using tissue homogenizer and centrifuged at $4000 \mathrm{rpm} / 15 \mathrm{~min}$ at $4^{\circ} \mathrm{C}$. The supernatant was washed and subjected to assay the activity of catalase (Aebi., 1984), reduced glutathione (Beutler et al., 1963 ) and acetylcholinesterase (Ellman et al., 1961 )Lipid peroxidation (LPO ) was measured by estimation of thiobarbituric acid reactive substance (TBARS )method of Ohkawa et al.(1979).

\subsection{1 .Genomic DNA isolation:}

Extraction of genomic DNA was done from cerebrum and cerebellum samples using QIAamp DNA Mini Kit (Qiagen)according to the manufacturer instructions.

\subsection{2 .Polymerase chain reaction (PCR).}

PCR reactions were performed in a $20 \mu$ l volume containing $1 \mu$ I DNA ( approx 100 $\mathrm{ng}$ ) as template, $2 \mu \mathrm{l} 10 \mathrm{x}$ reaction buffer (Promega, UK) $2 \mu \mathrm{l} 2 \mathrm{mM}$ dNTPs, magnesium chloride $1 \mathrm{mM}, 0.2 \mu \mathrm{l}$ of each primer pair $(200 \mathrm{ng} \mu \mathrm{l}-1)$ forward GTG GTA CCG TAT GAG CCA CC and reverse CAA CCT GGC ACA CAG CTT CC) 1 unit Go Taq polymerase (Promega,UK) PCR cycling was as follows : $94^{\circ} \mathrm{C}$ for $5 \mathrm{~min}, 35$ cycles of $94^{\circ} \mathrm{C}$ for $1 \mathrm{~min}$, $: 59^{\circ} \mathrm{C}$ for $1 \mathrm{~min}$ and $72^{\circ} \mathrm{C}$ for $1 \mathrm{~min}$; with a final $10 \mathrm{~min}$ at $72^{\circ} \mathrm{C}$. PCR was generated to amplify a 157 bp fragment flanking exon 7 as described by Gouda et al. (2008) and 72 bp of $\mathrm{H}$ Ras flanking exon 12 forward primer GGAGACCCTGTAGGAGGACCC and reverse primer TCTATAGTGGGGTCGTATTCGTCC Sakamoto et al. ( 2011).

\subsection{3 .Single strand conformation polymorphism (SSCP).}

Aliquots $(2 \mu \mathrm{l})$ from the PCR reaction were mixed with $10 \mu \mathrm{l}$ of SSCP dye $) 95 \%$ formamide, $5 \mathrm{mM}$ sodium hydroxide, $0.1 \%$ bromophenol blue, $0.1 \% x y l e n e$ cyanol( heated to $95^{\circ} \mathrm{C}$ for $5 \mathrm{~min}$, immediately chilled on ice and the samples were then electrophoresed in $15 \%$ PAGE in $1 \times$ TBE buffer at $150 \mathrm{~V}$ for $5 \mathrm{~min}$, then at $80 \mathrm{~V}$ at room 
temperature until the blue dye reached the bottom of the gel (Liechti-Gallati et al., 1999 ).The gel was stained with ethidium bromide $(1 \mathrm{mg} / \mathrm{ml})$ for $2 \mathrm{~min}$ and then destained in deionized water for $15 \mathrm{~min}$.Gels were visualized under a UV transilluminator and photographed.

\subsubsection{Brain amino acid concentrations:}

Amino acid in cerebrum and cerebellum homogenates were estimated by HPLC using percolumn PTC derivatization technique according to Heinrikson and Meredith (1984).

\section{6 .Statistical analysis.}

The GRAPHPAD (ISI Software, Philadelphia, PA, USA) computer program was used to conduct regression analysis and to plot the collected data .Data were expressed as means standard error of means) SE . (Assessment of the results was performed using one-way analysis of variance (ANOVA )procedure followed by Tukey-Kramer multiple comparison post-tests .Statistical analyses were performed using Software GRAPHPAD INSTAT (Version 2)The 0.05 level of probability was used as the criterion for significance.

\section{3 .RESULTS AND DISCUSSION}

\section{1 .Effect of deltamethrin on brain biochemical parameters:}

The activity of catalase (CAT) concentration of reduced glutathione (GSH) and lipid peroxidation (LPO )expressed as (MDA )and activity of Acetylcholinesterase (ChE )in cerebrum and cerebellum of experimental rats were recorded in tables ( 1 and 2)Treatment with deltamethrin for 30 days resulted in a significant $(P \leq 0.05)$ decrease in the activities of catalase and Acetylcholinestrase and concentration of reduced glutathione, while the level of lipid peroxidation showed significant $(P \leq 0.05)$ increase in the two regions of exposed rats brain in comparison with the control group .The $\mathrm{co}^{-}$ administration of green tea extract or vitamin $E$ alone or in combination with deltamethrin normalized the elevation of lipid peroxidation and reduction in the level of GSH content, activities of CAT and ChE in brain of exposed rats in addition to decrease of LPO level in comparison to deltamethrin treated group in both cerebrum and cerebellum.

Deltamethrin is widely used in agriculture and public health preservation programs for farm animals and pests. It is one of the environmental pollutants which showed a broad spectrum toxicological effects and biochemical dysfunction constituting serious 
hazards to health. Reactive oxygen species (ROS) including free radicals and other highly reactive form of oxygen are produced in cells during normal metabolic processes involving oxygen. ROS are released during cellular respiration, processes of biosynthesis and biodegradation, biotransformation of xenobiotics and phagocyte activation (Yaduvanshi et al., 2010) However, the levels of ROS may be significantly increased by exposure to different environmental toxins including pesticides .The reaction of free radicals and oxidants with lipid, protein and DNA produces potentially harmful effects . Results of the present study clearly reveal that Deltamethrin exposure causes increase in the level of lipid peroxidation in brain tissue of rats At the same time, deltamethrin exposure induced a significant decrease in the activity of catalase enzyme and the level of reduced glutathione in brain tissue of exposed rats .Deltamethrin induced an increase in the level of lipid peroxidation which is indicative of involvement of free radical mediated mechanism in its toxicity.

The elevation in lipid peroxidation and the reduction in the antioxidant enzyme (CAT) and glutathione content in rat brain might be attributed to the metabolic activation of Deltamethrin, which is considered as a major mechanism of its toxicity . Deltamethrin caused significant oxidative stress in brain tissue of exposed rats as was evident by the elevation of lipid peroxidation level and reduced level of total glutathione .Catalase is considered as one of the most important defense mechanism against toxic effects of oxygen metabolism .CAT helps in the removal of $\mathrm{H}_{2} \mathrm{O}_{2}$ formed during the reaction catalized by SOD enzyme .Many by-products of oxygen metabolism initiate different outcomes at the subcellular level .The superoxide radical has been shown to inhibit the activity of $\mathrm{GP}_{\mathrm{x}}$ and CAT activity .Enzymes that scavenge oxygen free radicals like CAT and SOD decreased by 50 \%upon pesticide exposure (Gabbianelli et al., 2002 ).

Glutathione is an important antioxidant agent in most cells .It plays a key role as a cofactor with variety of enzymes including $\mathrm{GP}_{\mathrm{x}}$. Glutathione depletion has been shown to intensify lipid peroxidation and predispose cells to oxidant damage .A significant depletion of glutathione along with a concomitant decrease in the activity of CAT was noted in the present study. In addition, GSH also participates in the detoxification of xenobiotics as a substrate for the enzyme glutathione-S-transferase (Kale et al., 1999).

The marked neurotoxic effect of deltamethrin may be attributed to that central nervous system is particularly susceptible to toxic effects of ROS due to low levels of antioxidant enzymes and glutathione, high concentration of iron and readily oxidizable 
substances such as polyunsaturated fatty acids and catecholamine, high rate of oxidative metabolic activity and highest accumulation of thiobarbituric acid reactive substance (TBARS.) In the present research, data collected on brain ChE activity proved that deltamethrin is an effective anticholinesterases agent, since the enzyme activity was inhibited in brain tissue in deltamethrin-treated group . This finding runs in parallel with the previous studies on pyrethroid insecticides (Hussien et al., 2013 )Several investigators have attributed this inhibition to attachment of pyrethroids to the ends of cholinergic nerve fibers that inhibit release of actylecholinestrase. This effect might also be due to inhibited AChE synthesis and/or increased degradation in brain tissue by deltamethrin intoxication.

Many insecticides are hydrophobic molecules that bind extensively to biological membranes, especially phospholipid bilayers and they may damage the membranes by inducing lipid peroxidation. Since Vit. E is known to be antioxidant, a number of studies have been performed to determine whether they can ameliorate the toxic effects of pesticides .In the present study coadminist ration of Vit. E with deltamethrin induced marked protective effect against the neurotoxicity of deltamethrin in exposed rats. This protective effect was manifested by the ameliorative brain damage besides improving the level of antioxidants and reduced level of lipid peroxidation .Vit. E (a-Tocopherol) is the major lipid-soluble antioxidant and is known to protect cellular membranes and lipoproteins from peroxidation (Yavuz et al., 2004 )may effectively minimize lipid peroxidation in biological systems .Vit. E allows free radicals to abstract a hydrogen atom from the antioxidant molecule rather than from polyunsaturated fatty acids, thus breaking the chain of free radicals reaction. Our results regarding the protective effect of Vit. E against the neurotoxicity of deltamethrin in rats were in accordance with data performed by Ali (2012).

The results from this study suggest that green tea extract (GTE) exhibits antioxidant effects against Deltamethrin-induced oxidative stress by preventing not only elevated MDA levels but also depleted GSH levels and by attenuating the depletion of antioxidant enzyme activities (CAT) It has been reported that phenolic compounds, such as catechins of GTE can react with superoxide radicals via one electron transfer mechanism or by a hydrogen mechanism to form corresponding semi-quinon .In addition, polyphenols can inhibit xanthine oxidase. This is possible due to its content of polyphenols that are characterized by their ability to scavenge free radicals produced during the aging process as well as ethanol metabolism . Efficacy of their activity in 
other tissues such as liver and blood has already been demonstrated (Dobrzynska et al., 2005 ).

Tea catechins are strong scavengers against superoxide hydrogen peroxide, hydrogen radicals and nitric oxide produced by various chemicals (Khalaf et al., 2012 ) .The most abundant polyphenols such as epigallocatechingallate and epicatechingallate contained in green tea scavenge a wide range of free radicals including the most active hydroxyl radical, which may initiate lipid and protein oxidative modification . Furthermore, the green tea polyphenols have been demonstrated to inhibit ironinduced oxidation of synaptosomes by scavenging hydroxyl radicals generated in the lecithin/lipooxidasesystem

Table 1. Effect of deltamethrin on Cerebrum biochemical parameters.

\begin{tabular}{|c|c|c|c|c|c|}
\hline Groups & Control & Deltamethrin & $\begin{array}{c}\text { Deltamethrin }+ \text { Green } \\
\text { Tea }\end{array}$ & Deltamethrin +Vit E & $\begin{array}{l}\text { Deltamethrin + } \\
\text { Green tea +Vit E }\end{array}$ \\
\hline CAT (U/g .Tissue) & $354.05 \pm 23.80$ & $265.28 \pm 15.26^{\circ}$ & $335.91 \pm 13.95^{b}$ & $346.69 \pm 15.18^{b}$ & $345.65 \pm 8.84^{b}$ \\
\hline GSH(mg/g. Tissue) & $18.98 \pm 8.49$ & $14.25 \pm 6.37^{\mathrm{a}}$ & $23.52 \pm 10.52^{a, b}$ & $24.62 \pm 11.01$ a,b & $25.43 \pm 11.37^{a, b}$ \\
\hline LPO(nmole/g tissue ) & $15.97 \pm 0.73$ & $22.41 \pm 1.49^{\mathrm{a}}$ & $16.69 \pm 0.34$ & $17.29 \pm 1.83$ & $16.01 \pm 0.80^{\circ}$ \\
\hline ChE(U/g .tissue ) & $3.88 \pm 0.07$ & $3.02 \pm 0.02^{\circ}$ & $3.50 \pm 0.06^{a, b}$ & $3.57 \pm 0.08^{a, b}$ & $3.51 \pm 0.02^{\mathrm{a}, \mathrm{b}}$ \\
\hline
\end{tabular}

Data expressed as mean $\pm \mathrm{S} . \mathrm{E}(\cdot \mathrm{n}=5$ animals $)$.

(a) Significant different from corresponding control group by one-way ANOVA at $P \leq 0.05$.

(b) Significant different from corresponding deltamethrin group by one-way ANOVA at $P \leq 0.05$.

Table 2 . Effect of deltamethrin on some Cerebellum biochemical parameters.

\begin{tabular}{|c|c|c|c|c|c|}
\hline Groups & Control & Deltamethrin & $\begin{array}{c}\text { Deltamethrin +Green } \\
\text { Tea }\end{array}$ & Deltamethrin +Vit. E & $\begin{array}{c}\text { Deltamethrin }+ \text { Green } \\
\text { tea }+ \text { Vit. E }\end{array}$ \\
\hline CAT (U/g . Tissue) & $378.45 \pm 20.50$ & $284.79 \pm 12.19^{a}$ & $352.75 \pm 10.38^{b}$ & $351.09 \pm 15.00^{b}$ & $366.83 \pm 12.93^{b}$ \\
\hline GSH(mg/g . Tissue) & $20.81 \pm 0.72$ & $15.51 \pm 0.48^{a}$ & $21.78 \pm 1.54^{b}$ & $20.03 \pm 0.67$ & $22.48 \pm 1.05^{b}$ \\
\hline LPO(nmole/g tissue ) & $14.44 \pm 0.22$ & $22.29 \pm 1.90^{\circ}$ & $15.15 \pm 0.31^{b}$ & $15.62 \pm 1.24^{b}$ & $15.01 \pm 0.51^{b}$ \\
\hline ChE(U/g tissue ) & $3.74 \pm 0.07$ & $2.85 \pm 0.04^{a}$ & $3.36 \pm 0.03^{a, b}$ & $3.42 \pm 0.07^{a, b}$ & $3.43 \pm 0.05^{a, b}$ \\
\hline
\end{tabular}

Data expressed as mean \pm S.E( $. n=5$ animals $)$.

(a) Significant different from corresponding control group by one-way ANOVA at $P \leq 0.05$.

(b) Significant different from corresponding deltamethrin group by one-way ANOVA at $P \leq 0.05$.

\section{2 .Genotoxicity of deltamethrin.}

The PCR products of cerebrum and cerebellum DNA from tissue samples were analyzed by SSCP to identify DNA harboring mutations, which were identified as band shifts .Figures $(1 \& 2)$ shows a representation of several samples that exhibited an abnormal band migration relative to normal tissue control.By PCR/SSCP, There are no mutational hotspots among the negative control group in p53gene .On the other hand, we observed $75 \%$ frequency in the cerebrum and $55 \%$ in the cerebellum of control positive groups which were treated by deltamethrin, a significant decrease was 
observed in all treated groups. In the deltamethrin with Vit. E group, 34 \%of cerebrum and $26 \%$ of cerebellum samples exhibited abnormal band migration, while in the deltamethrin with green tea group, a mutation rate of $48 \%$ in cerebrum and $32 \%$ in cerebellum samples are reported .As for deltamethrin, green tea and Vit. E groups, $27 \%$ of cerebrum and $26 \%$ of cerebellum samples exhibited abnormal band migration.

P53 gene "the guardian of genome" is the most frequently mutated tumor suppressor gene identified in human cancer .P53 inactivation leads to decreased DNA repair, and increased genomic instability, furthermore, given the fact that $p 53$ tumor suppressor gene mutations have been associated with progression towards more aggressive cancer or disease. Ras gene families consist of 3 members : $\mathrm{N}-$ ras, $\mathrm{H}$-ras and $\mathrm{K}$-ras, that encode for the highly homologous protein called $p 21$ according to their molecular weights. The inactivation of ras genes by point mutation is the most frequent and well known genetic alteration associated with human cancer including brain tumors .Common mechanisms of inactivation of these genes include missense mutations at the well-known hot spots of codon 12,13 and 16 (Gomori et al., 1999). Molecular abnormalities associated with primary brain tumors include a wide variety of changes in tumor suppressor genes, proto-oncogenes and growth factors. Mutations in the $\mathrm{p} 53$ and $\mathrm{H}$-Ras genes can be detected by several different methods including SSCP . The SSCP protocol that was employed in this research is inexpensive, easy, rapid, and gives no false positive results .Under non denaturing electrophoretic conditions, migration of single strand DNA is a function of its conformation, which depends on its sequence .Even single point mutations can be detected by variant migration patterns or by the presence of additional bands. 

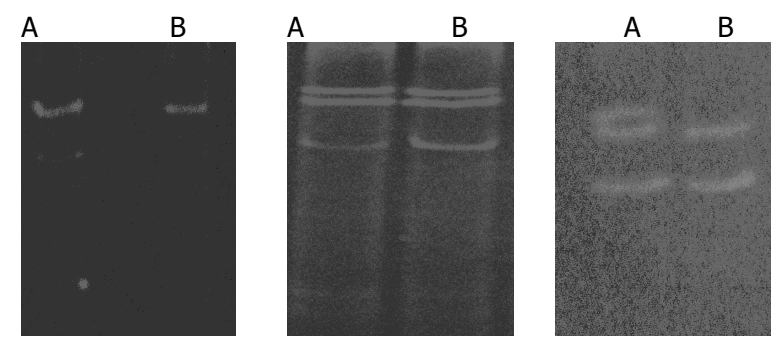

Deltamethrin\&Vit E

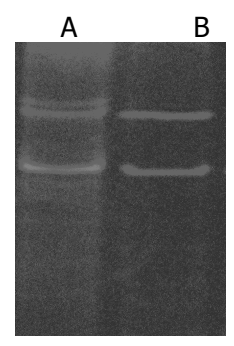

Deltamethrin\& Green Tea

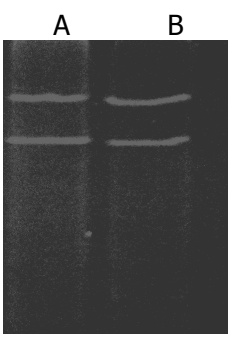

Deltamethrin, Vit . E\& Green Tea

\section{Fig. 1. SSCP analysis of exon (7) of p53 gene.}

cerebrum and cerebellum sample containing mutation are shown for each group .

Samples that revealed mobility shift in their migration during SSCP screening mutation analysis are only shown .

(A)cerebrum, (B )cerebellum.

\section{Fig. 2. SSCP analysis of exon (12) of H Ras gene.}

Cerebrum and cerebellum sample containing mutation are shown for each group .

Samples that revealed mobility shift in their migration during SSCP screening mutation analysis are only shown .

(A) Cerebrum, (B)Cerebellum.

Fig. 3. The percentage of gene mutation in exon (7) of P53 gene.

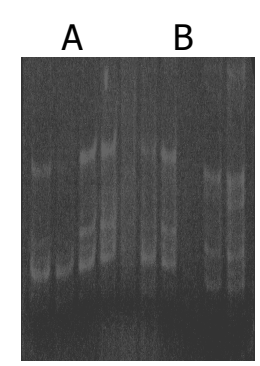

Negative control

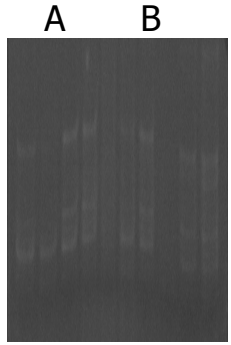

Deltamethrin

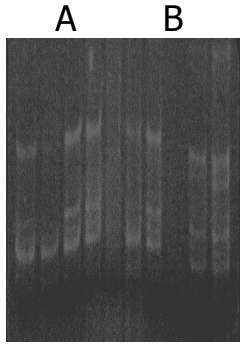

Deltamethrin\&Vit E

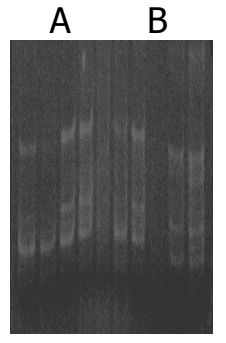

Deltamethrin\&

Green Tea

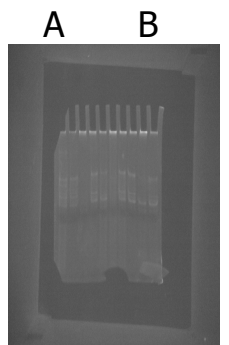

Deltamethrin, Vit .E\& Green

Tea

Fig 4.The percentage of gene mutation in exon (12) of $\mathrm{H}$ Ras gene.

Results of $\mathrm{H}$ ras gene, Figures ( $3 \& 4$ ), showed no mutations among the negative control group, whereas, 55 \%frequency in the cerebrum and $43 \%$ of the cerebellum were recorded in the control positive groups treated by deltamethrin .In the deltamethrin with Vit. E group, 22 \%of cerebrum and 14 \%of cerebellum samples exhibited abnormal 
band migration. While in the deltamethrin with green tea group, a mutation rate of $35 \%$ in cerebrum and $22 \%$ in cerebellum samples are reported .As for deltamethrin, green tea and Vit. E group, 21 \%of cerebrum and19 \%of cerebellum samples exhibited abnormal band migration.

\subsection{Brain amino acids:}

A .Cerebrum amino acid concentrations:

\section{A.1 Aspartic acid level (ASP).}

As Shown in table (3) subacute DM intoxication induced a significant increase in brain aspartic acid (excitatory amino acid )level among DM treated group versus the control group co administration of DM with vit. E or green tea extract or both revealed significant decrease in cerebral ASP concentration in comparison to that of DM treated group combination of green tea +vitamin E with DM give good improvement .

A-2 Glutamic acid level (Glu).

As shown in table (3 ) DM intoxication induced significant increase in cerebral Glu (excitatory amino acid )level in treated rats as compared to the control value .In contrast, a significant reduction in Glu levels were demonstrated in rat groups received DM in combination with vitamin $\mathrm{E}$ or green tea or its combination . The greatest reduction in glutamic acid levels was recorded in the last group (DM+Vit. E + green tea extract)

A3-Glycine (Gly )level.

Data presented in table (3) revealed a significant rise in cerebral (Gly )inhibitory amino acid (level in DM treated group versus the control group .Vit. E or green tea supplementation alone with DM failed to correct the significant rise in Gly level .While combination of both vitamin E +green tea extract together with DM induced marked and significant decrease in Gly level and the value near control value .

A-4 Taurine (Tau ) level.

As shown in table (3) DM intoxication failed to induce significant changes in cerebral Tyr level in treated rats . Consequently co administration of DM with vitamin $E$ or green tea extract or its combination together failed to induce any changes in cerebral Tyr level as compared to control value.

A-5 GABA.

The obtained data in table (3 )revealed that intoxication of DM to rats induced marked and significant rise in cerebral GABA (inhibitory amino acid )level as compared 
to that of control value.Also significant increase in GABA level was observed in both groups received DM with vitamin E or with green tea extract as compared to the control value but showed significant reduction than that of DM treated group .

In the same time, combination of vitamin $E$ and green tea extract with DM induced significant decrease in GABA level in comparison to DM treated value.

B-cerebellum amino acids:

B-1 -Aspartic acid level (ASP).

Data presented in table (4)revealed a significant increase in cerebellum ASP level in DM treated rats as compared to the control value .Coadministration of Vit E or green tea alone or in combination to DM induced protective effect which reflected by significant decrease in ASP levels in comparison to DM treated group.

B-2 Glutamic acid level (Glu).

The obtained data in table (4)revealed that DM intoxication induced marked and significant increase in cerebellum Glu level in brain of DM treated rats as compared to the control group .In contrast supplementation of vit $\mathrm{E}$ or green tea extract alone or combination of both with DM revealed significant inhibition in cerebellum Glu levels as compared to DM treated group.

B-3 Glycine( Gly )levels.

An s shown in table (4)significant elevation was demonstrated in cerebellum Gly (inhibitory amino acid )among DM treated group .While in experimental groups received green tea extract or Vit. E or both in combination with DM, a significant inhibition in Gly levels were revealed as compared to that of DM treated group . Maximum inhibition in Gly levels was observed in the last group received combination of $\mathrm{DM}+$ green tea+Vit. E as compared to control value.

B-4 Taurine (Tau )level.

The present results in table (4)demonstrate significant elevation in tau level in cerebellum of DM treated rats as compared to control value. While in experimental groups received DM beside green tea or Vit E or both showed significant decrease in tau levels as compared to the DM treated value.

B-5-GABA levels.

As demonstrated in table (4) cerebellum GABA (inhibitory amino acid )level showed a marked and significant rise in DM treated group as compared to the control value. Also the obtained results revealed that green tea extract or Vit. E in combination with DM failed to induce protective effect and the values of GABA were significant rise 
in compared to that of control value, but were significantly lower than that of DM treated value. While combination of green tea extract and Vit. E with DM induced significant inhibition in GABA levels as compared to DM treated group and the value nearly similar to that of control value. Amino acid concentration $(\mathrm{Ug} / \mathrm{g}$ tissue $)$ in cerebrum of rats exposed to deltamethrin alone of in combination with vitamin $\mathrm{E}$ or green tea extract or both.

Table 3. Amino acid concentration ( $\mathrm{Ug} / \mathrm{g}$ tissue) in cerebrum of rats exposed to deltamethrin alone of in combination with vitamin $\mathrm{E}$ and /or green tea extract or both.

\begin{tabular}{|l|l|l|l|l|l|}
\hline Parameters & Control & Deltamethrin & DM +green tea & DM +Vit. E & DM+green tea +Vit E. \\
\hline Aspartic acid & $1.096 \pm 0.11$ & $1.183 \pm 0.12 \mathrm{a}$ & $1.110 \pm 0.12 \mathrm{~b}$ & $1.15 \pm 0.11 \mathrm{~b}$ & $1.023 \pm 0.12 \mathrm{~b}$ \\
\hline Glutamic acid & $1.389 \pm 0.12$ & $1.496 \pm 0.13 \mathrm{a}$ & $1.399 \pm 0.13 \mathrm{~b}$ & $1.335 \pm 0.12 \mathrm{~b}$ & $1.328 \pm 0.12 \mathrm{~b}$ \\
\hline Glycine & $0.508 \pm 0.05$ & $0.536 \pm 0.05 \mathrm{a}$ & $0.520 \pm 0.04$ & $0.518 \pm 0.05$ & $0.488 \pm 0.04 \mathrm{~b}$ \\
\hline Taurine & $0.414 \pm 0.04$ & $0.436 \pm 0.03$ & $0.417 \pm 0.03$ & $0.413 \pm 0.03 \mathrm{a}, \mathrm{b}$ & $0.403 \pm 0.04$ \\
\hline GABA & $1.85 \pm 0.13$ & $3.81 \pm 0.24 \mathrm{a}$ & $2.65 \pm 0.17 \mathrm{a}, \mathrm{b}$ & $2.55 \pm 0.15$ & $1.8 \pm 0.04$ \\
\hline
\end{tabular}

Data expressed as mean $\pm \mathrm{S}$.E( $\cdot \mathrm{n}=5$ animals $)$.

(a )Significant different from corresponding control group by one-way ANOVA at $P \leq 0.05$.

(b ) Significant different from corresponding deltamethrin group by one-way ANOVA at $P \leq 0.05$.

Table 4. Amino acid concentration ( $\mathrm{Gg} / \mathrm{g}$ tissue) in cerebellum of rats exposed to deltamethrin alone of in combination with vitamin $\mathrm{E}$ and /or green tea extract or both.

\begin{tabular}{|l|l|l|l|l|l|}
\hline Parameters & Control & Deltamethrin & DM +green tea & DM +Vit. E & $\begin{array}{l}\text { DM+green tea } \\
+ \text { Vit. E }\end{array}$ \\
\hline Aspartic acid & $1.104 \pm 0.11$ & $1.341 \pm 0.12 \mathrm{a}$ & $1.127 \pm 0.09 \mathrm{~b}$ & $1.084 \pm 0.11 \mathrm{~b}$ & $0.980 \pm 0.081 \mathrm{~b}$ \\
\hline Glutamic acid & $1.478 \pm 0.12$ & $1.933 \pm 0.13 \mathrm{a}$ & $1.541 \pm 0.13 \mathrm{~b}$ & $1.410 \pm 0.13 \mathrm{~b}$ & $1.361 \pm 0.12 \mathrm{~b}$ \\
\hline Glycine & $0.556 \pm 0.05$ & $0.786 \pm 0.06 \mathrm{a}$ & $0.599 \pm 0.05 \mathrm{~b}$ & $0.576 \pm 0.07 \mathrm{~b}$ & $0.520 \pm 0.04 \mathrm{~b}$ \\
\hline Taurine & $0.486 \pm 0.03$ & $0.588 \pm 0.04 \mathrm{a}$ & $0.482 \pm 0.03 \mathrm{~b}$ & $0.485 \pm 0.04 \mathrm{~b}$ & $0.385 \pm 0.03 \mathrm{~b}$ \\
\hline GABA & $2.16 \pm 0.31$ & $5.79 \pm 0.52 \mathrm{a}$ & $3.86 \pm 0.23 \mathrm{a}, \mathrm{b}$ & $.27 \pm 0.22 \mathrm{a}, \mathrm{b}$ & $2.02 \pm 0.21 \mathrm{~b}$ \\
\hline
\end{tabular}

Data expressed as mean \pm S.E( $\cdot n=5$ animals).

(a) Significant different from corresponding control group by one-way ANOVA at $P \leq 0.05$.

(b) Significant different from corresponding deltamethrin group by one-way ANOVA at $P \leq 0.05$.

The effects of pyrethroids on the CNS are complex and may also involve antagonism of $\mathrm{Y}$-aminobutyric acid (GABA) modulation of nicotinic transmission, enhancement of noradrenaline release, and direct actions on calcium or chloride ion 
channels .Pyrethroids affect nervous system function by producing hyperexcitability in neurons (Murakami et al., 1992).

Thus, the ability of pyrethroid insecticides to cause apoptosis may contribute to the potential for high-level exposures to contribute to neurodegeneration. However, the mechanism by which pyrethroids, and in particular deltamethrin, induces apoptosis has not been established .Further studies identified the role of calpain and the endoplasmic reticulum (ER )stress pathway as mediators of deltamethrin-induced apoptosis. The prominent role of apoptosis, calpain and the ER stress pathway in neurodegeneration, these data provide mechanistic information as to how high-level exposure to pyrethroids could result in neurodegeneration (Vosler et al., 2008).

In conclusion, the sample percentage that revealed mobility shift in their migration during SSCP screening mutation analysis was significant among the control positive group such which deltamethrin caused high incidence of p53 mutations among cerebrum and cerebellum samples. The vitamin $\mathrm{E}$ and green tea are proved to protect against the mutational effect of deltamethrin .Vitamin $\mathrm{E}$ showed more protection compared to green tea whereas, the usage of both of them provided the most protection . The cerebrum samples are more affected by the deltamethrin than the cerebellum samples.

The obtained data revealed that exposure of rats to deltamethrin induced significant changes in the brain levels of some amino acids in cerebrum and cerebellum of intoxicated rats .It have been shown that DM induced significant elevation in ASP, Glu, Gly and GABA concentration in cerebellum of intoxicated rats.

The amino acids (AAs )such aspartic acid, glutamic acid, amino butyric acid (GABA)and 3,4dihydroxy phenylalanine (DOPA) is known to act as neurotransmitters in the central nervous system. They play an important role in response to neurodegenerative conditions. Neurotransmitter systems alterations can be implicated in seizures due to an increase in their oxidative metabolism or a decrease in their synthesis and or release and disturbance of glutamate and GABA metabolism showed to play an important role in the development of pyrethroid neurotoxicity . Excessive activation of glutamate receptors by excitatory amino acids leads to a number of deleterious consequences, including impairment of calcium buffering, generation of free radicals, activation of the mitochondrial permeability transition and secondary excitatory (KanunnKova, 2012 ).

The obtained results also explored remarkable increase in the brain levels of Gly in DM treated rats and in both examined parts (cerebrum and cerebellum )Glycine is an 
inhibitory glucogenicnon essential amino acid that can be synthesized from threonine and serine by a reversible reaction catalyzed by the enzyme serine trans hyroxymethylase Gly seen to be correlated with stimulated synthetic pathway and /or release of this neurotransmitter amino acid by subacute administration of DM( .Ahmed et al., 1992).

The present investigation has also revealed significant increase in Tau level in cerebellum of DM treated rats.This effect of DM is considered stimulatory effect on brain Tau .In general, taurine is an inhibitory neurotransmitter that initiates membrane polarization which results in decreased neuronal firing Also Taurine is also known to decrease $\mathrm{K}$ stimulated release of epinephrine and acetylcholine, which in turn support the present finding . Rise of taurine levels in the Bain seems to be correlated with damage be induced by DM, it might also be correlated to the stimulatory effect of DM on the synthesis and /or release of this amino acid neurotransmitter (Oja and Kontra, 1983).

The present investigation revealed that coadministration of Vit. E or green tea extract with deltamethrin DM or their combination attenuated the toxic effect of an evaluated brain amino acids. The data revealed that green tea extract induce protective effect more than that of Vit. $E$.in the same time combination of vit. $E$ \& green tea extract produce more protective effect against DM neurotoxicity than each alone .Little is known about the effects of antioxidant compounds in amino acid concentration in brain of adult rats exposed to pesticide toxicity

Green tea catechins have a wide spectrum of neuroprotective cellular mechanisms such as in chelation, scavenging free radicals, regulation of mitochondrial function and activation of survival genes and cell signaling pathways .EGCG is a powerful antioxidant and is 20 times than Vit. $\mathrm{E}$ in protecting essential brain lipids.It acts as an iron chelator in the brain, preventing iron from contributing to the production of EGCG also increases the activity of superoxide dismutase and catalase; antioxidant enzymes that help decrease free radical damage.They investigate the effect of EGCG on excitotoxic neuronal damage in a culture system .EGCG reduced excitotoxin induced MDA production and neuronal damage in the culture system .L-threonine is a unique amino acid present almost exclusively in the tea plant .It appears the amine competively inhibits glutamate transport into tumor cells, which causes decreased intracellular glutathione levels Regarding the protective effect of Vit. E or green tea extract against neurotoxic effect of DM 
In conclusion, exposure of rats to $1 / 10 L_{50}$ of deltamethrin for 1 month induced oxidative damage in cerebrum and cerebellum of treated rats. This damage represented by reduction in CAT, GSH and ChE levels .Also significant increase in MDA was recorded. Genotoxicity was detected by SSCP of HRas and P53 genes.Also DM induced significant alterations in the levels of some brain amino acid .Co administration of green tea extract of Vit. E alone or in combination with DM induced significant protective effect against the neurotoxicity of DM .combination of green tea extract +Vit E induce proper protective effect than each alone.

\section{4 .REFERENCES}

1. Aebi, H. 1984. Catalase in vitro .Methods Enzymol. 105:121-6.

2. Ahmed, N.A.; S.M. Rawis; N.M. Radwan and M. M. Attia. 1992. Comparative study on the neurotoxic effects of endrin and lannate in frog .J .Egypt .Ger .Soc .Zool . Comput .Physiol.,9:121-135.

3. Ali, Z .Y. .2012. Neurotoxic Effect of Lambda-Cyhalothrin, A Synthetic Pyrethroid Pesticide :Involvement of Oxidative Stress And Protective Role of Antioxidant Mixture .New York Science Journal .5(9 )93-105.

4. Assayed, M.E.; A.A. Khalaf and H.A. Salem 2010. :Protective effects of garlic extract and vitamin $C$ against in vivo cypermethrin induced cytogenetic damage in ratbone-marrow . Mutat Res. 702, 1-7 .

5. Behrens, S. and J. Karbers 1935. Determination of $L_{50}$.Archiv Fur expermintellepathologie und pharmakologie, 177-372.

6. Beutler, E.; O. Duron ; and B.M. Kelly. 1963. Improved method for the determination of blood glutathione .J Lab Clin Med. 61:882-8.

7. Dobrzynska, I.; B. Szachowicz-Petelska ; J. Ostrowska ; E. Skrzydlewska and Z. Figaszewski 2005.

Protective effect of green tea on erythrocyte membraneof different age rats int oxicated with ethanol. ChemBiol Interact. 156(1)41-53.

8. Ellman, G.L.; K.D. Courtney ; V .Andres and R.M. Feather-Stone. 1961. A new and rapid colorimetric determination of acetylcholinesterase activity . BiochemPharmacol. 7:88-95.

9. Frei, B. and J.V. Higdon. 2003. Antioxidant activity of tea polyphenols in vivo : evidence from animal studies .J Nutr.133:3275S-84S. 
10. Gabbianelli, R.; G. Falcioni ; C. Nasuti and F. Cantalamessa. 2002. Cypermethrininduced plasma membrane perturbation on erythrocytes from rats: reduction of $\mathrm{fl}$ uidity in thehydrophobic core and in glutathione peroxidase activity. Toxicol. 175:91-101.

11. Gomori, E.; T. Doezi; L. Pajor and A. Matolesy. 1999. Sporadic p53 mutations and absence of Ras mutations in Glioblastoma .Acta Neurochir (Wien) 141 :593 -599.

12. Gouda ,E.; A. Elbehairy and M. Ghoneim. 2008. Evaluation of antimutagenic efficacy of some natural compounds on cyclophosphamide-induced p53 alterations using PCR-SSCP .Z .Naturforsch .63c, 857-863.

13. Heinrikson, R.L.(1984): Meredith SC .Amino acid analysis by reverse-phase highperformance liquid chromatography :precolumnderivatization with phenylisothiocyanate .Anal Biochem. Jan;136(1)65-74.

14. Hfaiedh, N.; J.C. Murat and A. Elfeki. 2012. A combination of ascorbic acid and atocopherol or a combination of $\mathrm{Mg}$ and $\mathrm{Zn}$ are both able to reduce theadverse effects of lindane-poisoning on rat brain and liver .J Trace Elem Med Biol. 26:273-8.

15. Hussien, H.M.; H.M. Abdou and M.I. Yousef. 2013. Cypermethrin induced damage in genomic DNA and histopathological changes in brain and haematotoxicity in rats :the protective effect of sesame oil .Brain Res Bull. 92:76-83

16. Kale, M.; N. Rathore ; S. John and D. Bhatnagar. 1999. Lipid peroxidative damage on pyrethroid exposure and alterations in antioxidant status in rat erythrocytes :a possible involvement of reactive oxygen species .Toxicol Lett. 105:197-205.

17. Kanunn and N.P. Kova. 2012. Role of glutamic acid metabolism changes in neurodegenerative pathologies .J .biol. and earth sci., Vol 2 issue (1) 1-10.

18. Khalaf, A.A.; W.A. Moseley and M.I. Abdel-Hamed. 2012. The protective effect of green tea extract on lead induced oxidative and DNA d amage on rat brain . Neurotoxicol. 33(3):280-9.

19. Liechti-Gallati, S.; V. Schneider; D. Neeser and Kraemer. 1999.Two buffer page systembased SSCP/HD analysis of DNA and RNA :a general protocol for rapid and sensitive mutation screening in cystic fibrosis and any other human genetic disease .Eur J Hum Genet, 7:590-598.

20. Maiani, G.; M. Serafini ; M. Salucci ; E. Azzini and A. Ferro-Luzzi. 1977. 
Application of a new high performance liquid chromatographic method for measuring selected polyphenols inhuman plasma. J. Chromatogr B Biomed Sci Appl. 1997 May 9;692(2)311-7

21. Murakami, Y.; Y. Suzuki; Y. Kishimoto; S. Hirohashi; K. Hayashi and T. Sekiya. 1992. Detection of DNA aberrations in human cancers by single-strand conformation polymorphism analysis of polymerase chain reaction products . Tohoku J Exp Med;168:247-255

22. Ohkawa, H.; N. Ohishi and K. Yagi. 1979. Assay for lipid peroxides in animal tissues by thiobarbituric acid reaction .Anal Biochem. 95:351-8.

23. Oja, S.S. and P. Kontro. 1983. Taurine :in :handbook of neurochemistry .2nd edn.,Lajtha, A .plenum press, new york, pp :501-533.

24. Raina, R.; K. VermaP ; K. Pankajn And V. Kant. 2010. Protective role of L-ascorbic acid against cypermethrin-induced oxidative stress and lipid peroxidation in Wistar rats .Toxicological \& Environmental Chemistry.92:947-953

25. Sakamoto, A.; Y. Oda; T. Adachi; S. Tamiya; S. Matsuda; K. Tanaka; Y. Iwamoto and M. Tsuneyoshi. 2001. H-ras Oncogene Mutation in Dedifferentiated Liposarcoma Polymerase Chain Reaction-Restriction Fragment Length Polymorphism Analysis Am J ClinPathol 2001;115:235-242 235.

26. Vosler, P .S.; C .S. Brennan and J. Chen. 2008. Calpain-mediated signaling mechanisms in neuronal injury and neurodegeneration .Mol .Neurobiol .38, 78100.

27. Yaduvanshib, S.K.; A. Ojhab; S.C. Panta; V. Lomasha; N. Srivastavab. 2010. :Monocrotophos induced lipid peroxidation and oxidative DNA damage in rat tissues .Pesticide Biochemistry and Physiology, 97 :214-222.

28. Yavuz, T.; N. Delibas ; B. Yildirim ; I. Altuntas ; O. Candir ; A. Cora ; N. Karaman ; E. Ibrisim and A. Kutsal. 2004. Vascular wall damage in rats induced by methidathion and ameliorating effect of vitamins E and C .Arch Toxicol. 78:6559. 


\section{تأثير السميه العصبيه و الور اثيه للالتاميثرين والتأثير الوقائي

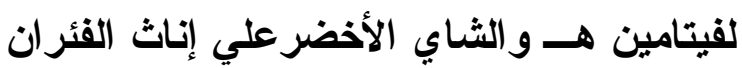

\section{عبد العظيم ع خلف 1 - مروه م إبراهيم2 - عادل ف تهامي1-عمرو ع عبد الله3}

1-قسم الطب الثرعي و السموم - كلية الطب البيطري- جامعة القاهره.

2-قسم الكيمياء الحيويه - كلية الطب البيطري- جامعة القاهره

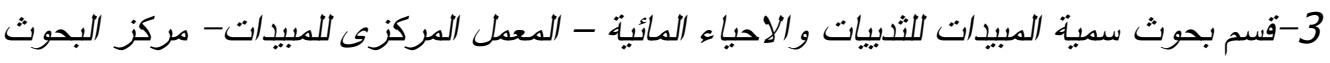

الزراعية.

العديد من الدراسات تؤكد أهمية الأجهاد التأكسدي و السميه الور اثيه كدليل للتأثير السام لمركبات

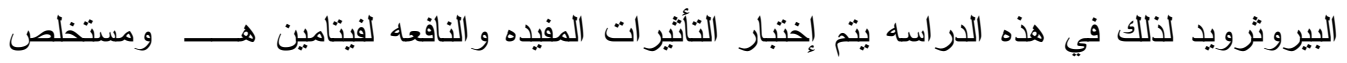

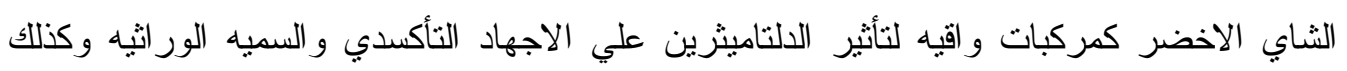
بعض الخلل في الاحماض الامينيه الناقله للتبار العصبي في المخ لاناث القئران البالغه. ينت إعطاء

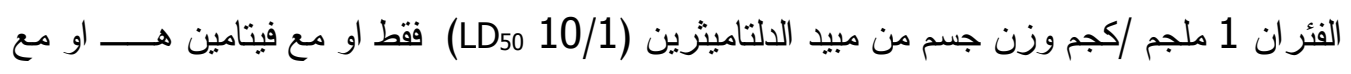
مستخلص الثاي الاخضر • ويتم قياس كل من إنزيم الكتاليز و الجلوناثيون المختزل وتقدير الدهون

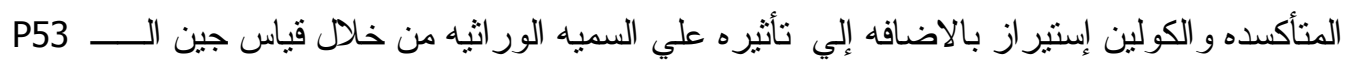

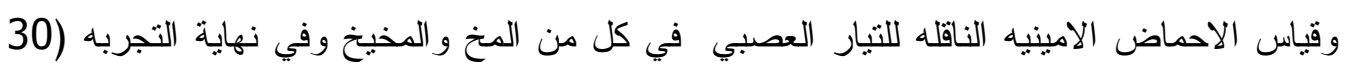

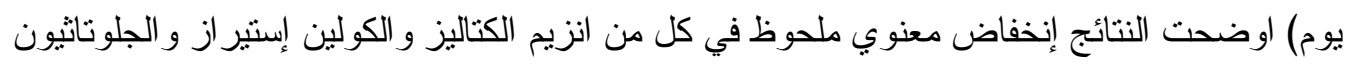

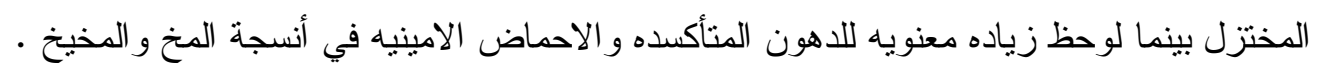

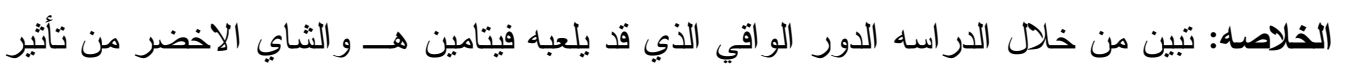

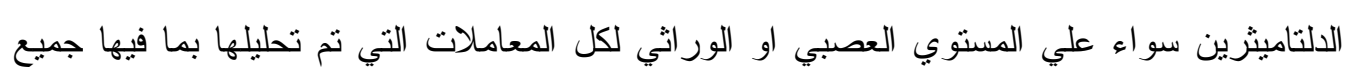

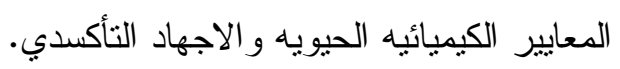


